\title{
Sudden infant death in Southampton and an evaluation of the Sheffield scoring system
}

\author{
J D C HARRIS, ${ }^{1}$ M RADFORD, ${ }^{2} M$ WAILOO, ${ }^{2}$ R G CARPENTER, ${ }^{3}$ AND \\ D MACHIN ${ }^{4}$
}

From the Faculty of Medicine, ${ }^{1}$ Child Health, ${ }^{2}$ and Community Medicine, ${ }^{4}$ University of Southampton, Southampton, and Department of Epidemiology and Medical Statistics, ${ }^{3}$ London School of Hygiene and Tropical Medicine, London, UK

SUMmaRY The cases of sudden infant death occurring in Southampton over the period 1 July 1975 to 31 December 1979 are reviewed with respect to "risk" factors identified in other studies. A retrospective case control study of 49 of these deaths and 98 controls was undertaken to evaluate the Sheffield scoring system. The study suggested that the Sheffield score might usefully be used prospectively in Southampton with only minor modification.

The development of a method for predicting at birth which babies are liable to die suddenly and unexpectedly at home ${ }^{1}$ has raised hopes of reducing the postneonatal infant mortality rate. By giving numerical weightings to eight obstetric and perinatal factors a score for each baby is obtaine $d^{2}$ that is related to the risk of unexpected death and in conjunction with health visitor surveillance has resulted in a reduced number of unexpected infant deaths in Sheffield (RG Carpenter et al, unpublished observations).

The value of score systems in general has been questioned $^{3}$ as has the applicability of the Sheffield system to other areas. ${ }^{4}$ Recent work has shown, however, that although the Sheffield system may not be directly applicable in other areas, minor modifications may yield a useful system. ${ }^{6}$

The purpose of this paper is to describe a retrospective review of the unexpected infant deaths in the Southampton Health District and, together with the use of suitable controls, to evaluate the Sheffield at-birth scoring system or some modification of it with a view to implementing a risk-related intervention programme.

Before 1 January 1980 no special attention (in the sense of follow-up procedures now used routinely in Sheffield) was given to following up particular groups of babies in Southampton.

\section{Materials and methods}

The sudden unexpected infant deaths in Southampton are given as part of a confidential list published by the Hampshire Area Health Authority. This study covers those babies on that list aged between 1 week and 2 years of age dying suddenly and unexpectedly between 1 July 1975 and 31 December 1979. All cases of sudden unexpected death were included even if a cause was later found at postmortem examination. Only sudden deaths of children with gross congenital abnormalities or malignancies were excluded. Our figures include some children who appear to have died in hospital rather than at home. These infants almost certainly died at home, although death was not certified until resuscitation in the accident and emergency department of Southampton General Hospital had been attempted.

For the determination of the Sheffield score the obstetric and perinatal histories of those children that could be traced to the birth registers of either the Southampton General Hospital or the Victoria House General Practitioner Maternity Unit were recorded. In addition, for each dead child two live controls were chosen. These were the children born immediately before and immediately after the index case, in the same maternity unit, and whose parents lived in Southampton at the time of birth. In the event of an index case being a twin the other twin was not used as a control.

Data on the eight relevant factors-maternal age, birthweight $(\mathrm{g})$, number of previous pregnancies, duration of second stage of labour ( $\mathrm{min}$ ), mother's blood group, twinning, feeding intention, and presence of urinary tract infection during pregnancy-were obtained. Cases and controls were then scored using the "at birth" system.

\section{Results}

SUDDEN INFANT DEATH IN SOUTHAMPTON The postperinatal mortality rate in Southampton for 
$1977-9$ was $6 \cdot 2$ per 1000 , slightly above the national average of 6.0 per 1000 for England and Wales. Table 1 shows the number of births, postperinatal deaths, and sudden infant deaths for the period 1 July 1975-31 December 1979 in Southampton. The seasonal distribution of the 68 sudden infant deaths is shown in the equi-areal rose diagram (fig 1) that takes into account the different numbers of days in different months, the leap year of 1976 , and the six months of data in 1975.

Figure 1 shows clearly the excess of deaths in the winter months of December, January, and February as has been previously reported. A formal test for the absence of seasonality described by $\mathrm{Mardia}^{7}$ was significant $\left(\chi^{2}=13 \cdot 7, \quad \mathrm{df}=2, \mathrm{p} \simeq 0.001\right)$ and suggested the peak incidence as the period around 1 January.

Table 1 Number of live births, postperinatal deaths, and unexpected infant deaths in Southampton, 1 July 1975-31 December 1979

\begin{tabular}{|c|c|c|c|c|c|}
\hline \multirow[b]{2}{*}{ Year } & \multirow{2}{*}{$\begin{array}{l}\text { Live } \\
\text { births }\end{array}$} & \multicolumn{2}{|c|}{ Postperinatal deaths } & \multicolumn{2}{|c|}{ Unexpected infant deaths } \\
\hline & & No & Rate/1000 & No & Rate/1000 \\
\hline 1975 & 4802 & 43 & $9 \cdot 0$ & $8^{*}$ & $3 \cdot 3$ \\
\hline 1976 & 4587 & 32 & $7 \cdot 0$ & 10 & $2 \cdot 2$ \\
\hline 1977 & 4407 & 27 & $6 \cdot 1$ & 18 & $4 \cdot 1$ \\
\hline 1978 & 4596 & 32 & $7 \cdot 0$ & 14 & $3 \cdot 0$ \\
\hline 1979 & 4924 & 27 & $5 \cdot 5$ & 18 & $3 \cdot 7$ \\
\hline year & 4663 & 32 & 6.9 & 15 & $3 \cdot 3$ \\
\hline
\end{tabular}

"From 1 July to 31 December 1975 only.

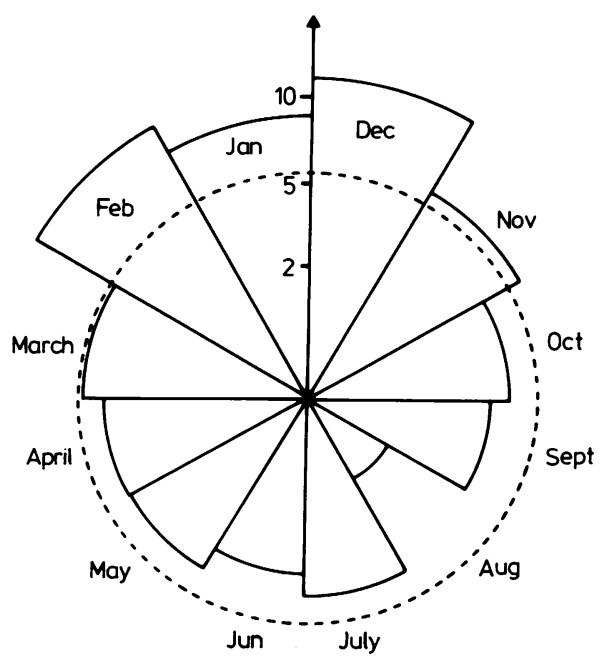

Fig 1 Seasonal variation in sudden infant deaths.

\section{EVALUATING THE SHEFFIELD SCORING SYSTEM}

\section{Material}

The parents of 50 of the 68 babies who died suddenly (table 1) lived in Southampton at the time of birth. The maternity notes on all but three were obtained. The remaining 18 were not born in Southampton. Two additional cases were added, one who died on 30 June 1975 the other on 24 January 1980. This gave a total of 49 cases and their corresponding 98 controls.

Factors influencing "survival" times of dead babies The age at death of the infants ranged from 18 to 434 days (median of 100 days). Figure 2 shows the survival curve of the 49 babies.

Of the eight factors included in the Sheffield at-birth score, only blood group appeared to effect the duration of survival among the index cases. Table 2 and fig 3 indicate an excess of early deaths among babies with maternal blood group $\mathrm{O}$, and later deaths among those of blood group $B$.

There were 34 male and 15 female deaths.

\section{Sheffield scores}

Table 3 compares the index cases and controls from Southampton with those 195 cases and 250 controls used by Carpenter $e t a l^{2}$ with respect to each variable

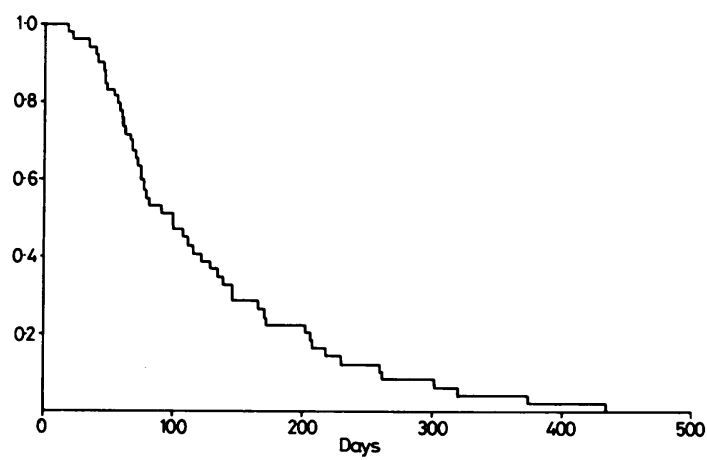

Fig 2 Survival curve for babies classified as sudden infant deaths in Southampton 1975-9.

Table 2 Observed deaths by mother's blood group* and expected deaths assuming equal survival rates

\begin{tabular}{lllll}
\hline $\begin{array}{l}\text { Mother's } \\
\text { blood } \\
\text { group }\end{array}$ & $\begin{array}{l}\text { No of } \\
\text { deaths }(O)\end{array}$ & $\begin{array}{l}\text { Expected } \\
\text { deaths }(E)\end{array}$ & O/E & Prob \\
\hline O & 14 & 7.8 & 1.79 & \\
A & 25 & 26.6 & 0.94 & 0.03 \\
B & 9 & 13.6 & 0.66 & \\
\hline
\end{tabular}

*The single case of an AB mother excluded. 
Table 3 Comparison of cases and controls from Southampton and Sheffield

\begin{tabular}{|c|c|c|c|c|}
\hline & \multicolumn{2}{|c|}{ Southampton } & \multicolumn{2}{|c|}{ Sheffield } \\
\hline & Cases & Controls & Cases & Controls \\
\hline No of infants & 49 & 98 & 195 & 250 \\
\hline Mother's age (years) & $23 \cdot 5$ & $26 \cdot 0$ & 23.7 & $26 \cdot 1$ \\
\hline Previous pregnancies (mean) & $1 \cdot 7$ & $1 \cdot 2$ & 1.8 & $1 \cdot 3$ \\
\hline \% Caesarian section & 12 & 7 & 3 & 6 \\
\hline Median duration of second stage of labour ( $\mathrm{min}$ ) & $17 \cdot 1$ & $22 \cdot 8$ & $15 \cdot 9$ & 23.4 \\
\hline \multicolumn{5}{|l|}{ \% Mother's blood group } \\
\hline o & 29 & 41 & 50 & 40 \\
\hline $\mathbf{A}$ & 51 & 46 & 34 & 51 \\
\hline B & 18 & 13 & 12 & 6 \\
\hline $\mathbf{A B}$ & 2 & $\mathbf{0}$ & 4 & 3 \\
\hline Mean birthweight (g) & 2981 & 3339 & 3042 & 3283 \\
\hline \% Twin birth & 10 & 0 & 6 & 4 \\
\hline \multicolumn{5}{|l|}{ \% Feeding intention } \\
\hline Breast only & 41 & 65 & 15 & 29 \\
\hline \multicolumn{5}{|l|}{ \% Urinary tract infection in pregnancy } \\
\hline Absent & 84 & 89 & 74 & 88 \\
\hline Query & 8 & 6 & 14 & 7 \\
\hline Present & 12 & 5 & 12 & 6 \\
\hline
\end{tabular}

used in the Sheffield scoring system (table 4). The Southampton cases and controls appear similar to those from the Sheffield area with respect to mother's age, number of previous pregnancies, birthweight, and duration of second stage of labour. The proportion of mothers with blood group $O$ in Southampton is $29 \%$ for the cases and $41 \%$ for the controls in contrast to $50 \%$ and $40 \%$ respectively in Sheffield.

The Sheffield scores for the 49 index and 98 control babies from Southampton were calculated in the standard way (table 4) and the resulting score distributions are shown in fig 4 . The mean score for the index cases was $494, S D=86$ and for the controls $421, \mathrm{SD}=72$.

It is clear from fig 4 that the proportion of cases $(47 \%)$ with a score in excess of 500 is greater than the corresponding proportion for the controls (13\%). A formal test of significance, incorporating the rest for

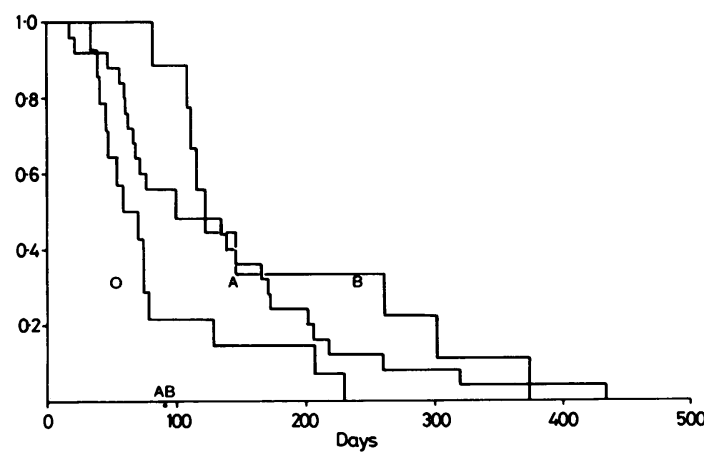

Fig 3 Survival curve for babies classified as sudden infant deaths in Southampton 1975-9 by mother's blood group. trend described by Armitage, ${ }^{8}$ is summarised in table 5 and is significant at $p<0.001$, suggesting an increasing proportion of cases with increasing Sheffield score.

Survival analysis using the three score groups in뭉 table 5 when applied to the index cases suggests noo association between score and time of death.

Table 4 Sheffield birth scoring system

\begin{tabular}{|c|c|c|}
\hline Item & & Score \\
\hline Mother's age & $10 \times(50$-age in years $)$ & \\
\hline \multirow{10}{*}{ Previous pregnancies } & $\mathbf{0}$ & $\mathbf{0}$ \\
\hline & 1 & 21 \\
\hline & 2 & 43 \\
\hline & 3 & 64 \\
\hline & 4 & 85 \\
\hline & 5 & 107 \\
\hline & 6 & 128 \\
\hline & 7 & 149 \\
\hline & 8 & 171 \\
\hline & 9 or more & 192 \\
\hline \multirow[t]{7}{*}{ Duration of 2nd stage of labour } & $<5 \min$ & 127 \\
\hline & 5-14 min & 100 \\
\hline & $15-29 \mathrm{~min}$ & 72 \\
\hline & $30 \mathrm{~min}-2 \mathrm{~h}$ & 45 \\
\hline & $>2 \mathrm{~h}$ & 18 \\
\hline & NA & 76 \\
\hline & Unknown & 76 \\
\hline \multirow[t]{2}{*}{ Mother's blood group } & O, B, AB & 44 \\
\hline & A & 0 \\
\hline \multirow[t]{7}{*}{ Birthweight (g) } & $<2000$ & 93 \\
\hline & $2000-2499$ & 78 \\
\hline & $2500-2999$ & 62 \\
\hline & $3000-3499$ & 47 \\
\hline & $3500-3999$ & 31 \\
\hline & $4000-4499$ & 16 \\
\hline & $4500-5500$ & $\mathbf{0}$ \\
\hline \multirow[t]{2}{*}{ Twin } & Yes & 103 \\
\hline & No & 0 \\
\hline \multirow[t]{2}{*}{ Feeding intention } & Breast only & $\mathbf{0}$ \\
\hline & Bottle or both & 33 \\
\hline \multirow[t]{3}{*}{ Urinary infection during pregnancy } & Yes & 54 \\
\hline & No & $\mathbf{0}$ \\
\hline & $?$ & 5 \\
\hline \multirow[t]{3}{*}{ Cut point for total score } & & 500 \\
\hline & High risk & 500 and over \\
\hline & Low risk & 499 and under \\
\hline
\end{tabular}




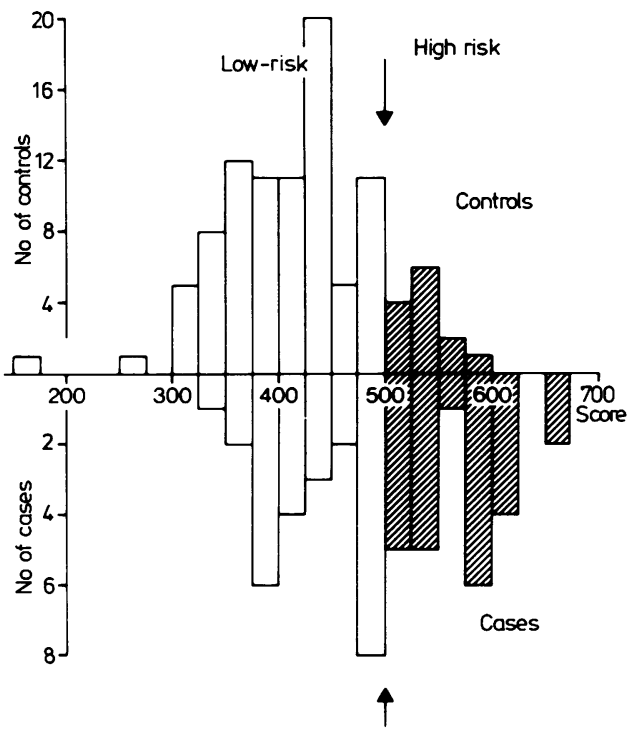

Fig 4 Distribution of Southampton scores using Sheffield system, (49 cases, 98 matched controls).

Table 5 Proportion of Southampton cases in three score groups

\begin{tabular}{lcccc}
\hline & \multicolumn{3}{l}{ Sheffield score } & \\
\cline { 2 - 4 } & $\leqslant 399$ & $400-499$ & $\geqslant 500$ & Total \\
\hline Cases & 9 & 17 & 23 & 49 \\
Controls & 38 & 47 & 13 & 98 \\
Total & 47 & 64 & 36 & 147 \\
Proportion of cases & 0.19 & 0.27 & 0.64 & \\
\hline
\end{tabular}

$\chi^{2}$ Trend, $1 \mathrm{df}=16.76, \mathrm{p}<0.001$.

\section{Sheffield score modifications for Southampton}

As there appear to be differences between the index cases and controls from Southampton and those of Sheffield with respect to some of the eight score variables summarised in table 3 it might be expected that using the method of discriminant analysis directly on the Southampton data would lead to improvement in separating cases from controls. Such a score system could be constructed, and one would expect the contribution of the variables to differ from that of the Sheffield system. The relevant analysis, however, is to determine whether the best predictor for the Southampton data represents a statistically significant improvement over the Sheffield score system.

The appropriate statistical theory described by Draper and Smith ${ }^{9}$ shows that the best approach is to calculate the Sheffield score $S$ for each of the Southampton cases and controls and to use stepwise discriminant analysis to investigate whether the discrimination achieved by $S$ is statistically improved by adding in either singly or in combination any of the eight variables investigated.

In the event the analysis suggested that the only modification needed relates to mother's blood group. The problem of different associations among two case-control groups in Sheffield in this respect has been discussed by Carpenter et al. ${ }^{2}$

In view of the heterogeneity of the data sets in this respect the analysis was repeated excluding blood group from the Sheffield score. The resulting scores, $\mathrm{S}^{*}$, could not be statistically significantly improved for the Southampton data either by any modification to the scores for the remaining seven variables or by including mother's blood group in some form. Reducing the cut point from 500 to $\mathbf{4 7 5}$ to allow for the omission of blood group S* allocated $57 \%$ of the Southampton cases to the high risk group as compared with $15 \%$ of the controls.

\section{Discussion}

Suggestion that a scoring system of this type developed in a northern industrial city could be applied to a southern area with such a degree of apparent success is surprising, since each of the constituent factors of that system, blood group and twinning apart, may be heavily influenced by socioeconomic and environmental factors and since the scoring system did not appear to work in other areas, notably Birmingham. ${ }^{40}$ Evaluation of the Sheffield system has since taken place in nine other areas and has been found to be both effective and potentially useful with minor modifications. ${ }^{6}$ That the mother's blood group should be the only modification suggested for Southampton adds weight to those findings, especially since removal of the variable does not significantly alter the influences of the other factors.

Crucial to a study of this nature is the manner of selection of the cases. Our major criteria for choosing index cases were whether or not death had occurred at home, and then labelled as "cot death" after full pathological examination. Even allowing for variations in clinical and pathological practices it seems that most cases studied here could be grouped in the same way as those in the original Sheffield study, ${ }^{11}$ while only two of our 49 cases could be classed as accidental death. Of the other cases in Southampton $69 \%$ were group D: no disease; $12 \%$ group C: minor disease; and 16\% group B: severe disease, compared with $33 \%, 37 \%$, and $19 \%$ in the Sheffield study. Thus most cases in both studies were group C and D. No group A children (longstanding disease) were included in either study. A further 
similarity of sex ratio, ages, and seasonal variations of the death between our cases and those in other studies confirms that we are studying typical cases of unexpected infant death..$^{12} 13$

The purpose of this study was to determine whether the criteria that existed could be used for detecting children at risk of cot death in Southampton and implemented within 48 hours of birth. The affirmative answer then raises the question: Is such a scoring system likely to be useful? Lewak et al constructed a remarkable system for identifying infants at risk based on eight factors. ${ }^{3}$ All eight risk factors were present in 56 of the 14259 infants studied and six (11\%) of these 56 infants died. Nevertheless, Lewak et al and more recently Valdes̀-Dapena" ${ }^{14}$ concluded that "scoring systems are not yet sensitive enough for clinical use."

The only possible grounds for not using a birth scoring test is that one does not know what to do for the high risk infant. In which case the least one could do would be to give them a fortnightly check up, as has been done in Sheffield with encouraging results. Further, a theoretical evaluation of the Southampton system based on theory developed by Carpenter (unpublished observation) suggests that $40 \%$ of the postperinatal mortality might be eliminated by allocating the same total care in relation to risk. We are therefore planning to submit the birth system of scoring and risk-related intervention as developed in Sheffield to a prospective field study, attempting to direct the attention of the primary care team to the babies at greatest risk. It should not be overlooked that early intervention in pregnancy to improve the general level of antenatal care of the mother might significantly improve the state of the baby at birth and hence reduce the risk of sudden infant death.

Requests for reprints to: D Machin, Community Medicine, Southampton General Hospital, Tremona Road, Southampton SO9 4XY.

\section{References}

${ }^{1}$ Protestos CD, Carpenter RG, McWeeny PM, Emery JL. Obstetric and perinatal histories of children who died unexpectedly (cot death). Arch Dis Child 1973; 48: 835-41.

${ }^{2}$ Carpenter RG, Gardner A, McWeeny PM, Emery JL. Multistage scoring system for identifying infants at risk of unexpected death. Arch Dis Child 1977; 52: 606-12.

${ }^{3}$ Lewak N, van den Berg BJ, Beckwith JB. Sudden infant death syndrome risk factors. Clin Paediatr 1979; 18: 404-11.

${ }^{4}$ Oakley JR, Tavare CJ, Stanton AN. Evaluation of the Sheffield system for identifying children at risk from unexpected death in infancy. Arch Dis Child 1978; 53: 649-52.

${ }^{5}$ Palmer SR, Siggins RD, Bewley BR. Infant deaths in inner London: a health care planning team study. Community Medicine 1980; 2: 102-8.

- Carpenter RG, Gardner A, Watson E. An epidemiological and sociological study of unexpected death in infancy in nine areas of Southern England. Med Sci Law 1981; 21: 1-7.

${ }^{7}$ Mardia KV. Statistics of directional data. London: Academic Press, 1972; 357.

${ }^{8}$ Armitage P. Statistical methods in medical research. Oxford: Blackwell. 1974: 504.

${ }^{\circ}$ Draper NR, Smith H. Applied regression analysis. New York: Wiley, 1966; 407.

${ }^{10}$ Carpenter RG, Gardner A, Emery JL. Evaluation of the Sheffield system for identifying children at risk from ${ }_{\mathbb{C}}$ unexpected death in infancy. Arch Dis Child 1979; 54:@

\begin{tabular}{l} 
406-7. \\
${ }^{11}$ Carpenter RG, Emery JL. Identification and follow-up of $\frac{0}{O} \mathrm{C}$ \\
\hline
\end{tabular} infants at risk of sudden death in infancy. Nature 1974,2 250: 729.

${ }^{12}$ Froggatt $P$, Lynas MA, Mackenzie G. Epidemiology ofo sudden unexpected deaths in infants (cot deaths) in Northern Ireland. Br J Prev Soc Med 1971; 25: 119-34

${ }^{13}$ Emery JL. Epidemiology of sudden unexpected or rapid? deaths in children. Br Med J 1959; ii: 925-8.

${ }^{14}$ Valdes̀-Dapena MA. Sudden infant death syndrome: a review of the medical literature 1974-1979. Paediatrics 1980; 66: 597-614. 